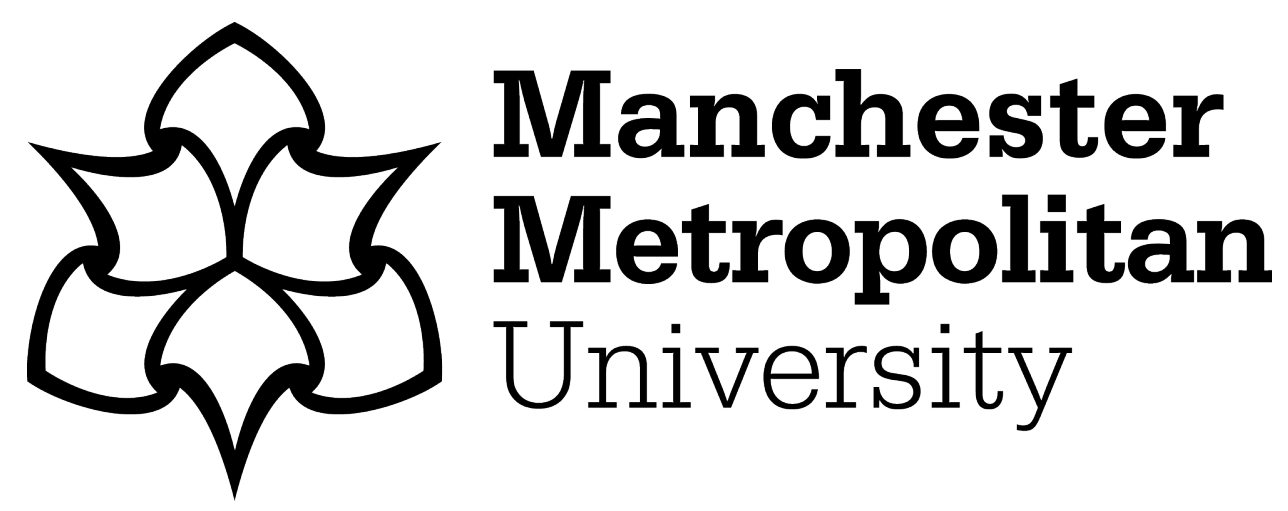

Veer-Ramjeawon, $P$ and Rowley, J ORCID logoORCID: https://orcid.org/0000-0003-3437-6914 (2020) Embedding knowledge management in higher education institutions (HEIs): a comparison between two countries. Studies in Higher Education, 45 (11). pp. 2324-2340. ISSN 0307-5079

Downloaded from: https://e-space.mmu.ac.uk/622827/

Version: Accepted Version

Publisher: Taylor \& Francis

DOI: https://doi.org/10.1080/03075079.2019.1608431

Please cite the published version 


\section{Embedding knowledge management in Higher Education Institutions (HEIs): a comparison between two countries}

\section{Authors:}

Poonam Veer-Ramjeawon, Open University of Mauritius, Reduit, Mauritius; pramjeawon@intnet.mu

Professor Jennifer Rowley, Manchester Metropolitan University, Manchester, UK; j.rowley@mmu.ac.uk 


\title{
Embedding knowledge management in Higher Education Institutions (HEIs): a comparison between two countries
}

\begin{abstract}
Previous research on knowledge management in universities has focused mainly on a single country. This research contributes by exploring the understanding of senior managers and academics involved in research/and research management and comparing the three KM processes in two countries, Mauritius and South Africa, one with a small and developing higher education sector and the other with a relatively well-developed higher education sector. Data were obtained through semi-structured interviews with key informants from thirteen HEIs from Mauritius and South Africa. The three KM processes adopted in the two countries had a lot of similarity with only a few differences. This article builds a profile of the similarities and differences between the two countries, and develops models of KM processes. This comparison acts as a basis for recommendations for improving research practices in HEIs and as a basis for innovation in the less developed country.
\end{abstract}

Keywords: Knowledge Management, Knowledge creation, Knowledge sharing, Knowledge transfer, Higher Education, Universities

Acknowledgements: The authors would like to acknowledge the support of the Mauritius Research Council. 


\section{Introduction}

The increasing pressure on universities to play a significant role in national innovation processes and economic development has significantly redefined the roles of universities worldwide (OECD 1997; Etzkowitz and Leydesdorff 2000; Philpott et al. 2011; Rinaldi et al. 2018). In order to respond to these changes, universities are expected to contribute to the creation of highly talented and knowledgeable workforces, and new knowledge to support the development of innovative and globally competitive national economies.

This paradigm shift required higher education institutions (HEIs) to develop innovative and appropriate tools, conducive strategies and policies in order to manage their most important resource 'knowledge'. This knowledge is created through research, shared through teaching and learning and transferred through communication, and job creation through spin-offs (Alexandropoulou et al. 2009). Moreover, the changing role of contemporary HEIs is closely associated with three knowledge management (KM) processes - knowledge creation, knowledge sharing and knowledge transfer (Rowley 2000; Alexandropoulou et al. 2009; Ramachandran et al. 2009; Fullwood et al. 2013; Fuller et al. 2017). Although all of these processes can be used by universities to fuel economic growth (Stamou 2017), many commentators have suggested that it is important that universities strategically position themselves as either teaching or research or entrepreneurial universities (Hewitt-Dundas 2012; Fuller et al. 2017; Fussy 2017). More specifically, since the African region lags in the 'generation of new knowledge' function, and is at the bottom of almost every indicator-based ranking for higher education, universities in Africa are expected to be 'engines of development' (Cloete and Maassen 2017, In: Muller et al. 2017). This expectation has led to rapid growth and internationalisation of the higher education sector in the sub-Saharan African (SSA) region, over the last four decades (UNESCO 2010), such that it has become increasingly important for the universities in this region to manage their knowledge processes, to ensure that they do not become 'irrelevant and more marginalized' (Cortez et al. 2011). However, previous research in various countries in the world, has shown that HEI's often do not have a clear knowledge management strategy (Cranfield and Taylor 2008), even though, incorporating KM practices as in the private sector and having a KM strategy could assist HEIs in the transformation process (Alexandropoulou et al. 2009; Trivella and Dimitrios 2015).

This paper presents a case study of two countries in the sub-Saharan African region, Mauritius and South Africa. The Republic of Mauritius, with a developing higher education sector, aspires to become a knowledge hub and a regional centre of excellence for higher education, such that it makes a significant contribution to the country's economic development. On the other hand, South Africa, with high ranking public universities in the region, has a well-developed higher education sector. Together, the two countries offer an interesting context for this research. Hence, the purpose of this research is to contribute to the negligible comparative research on KM in HEIs in two countries at different stages on their university development journey. More specifically, this paper aims to: explore and compare the three KM processes - knowledge creation (KC), knowledge sharing (KS) and knowledge transfer (KT), in two different countries. The research generates models of KM processes of their universities, and thereby identifies the similarities and differences between the two countries. This comparison acts as a basis for recommendations for improved knowledge management practices, which have the potential to support innovation in the less developed country. 
The following section of this article summarizes previous research on knowledge management and its processes, with specific reference to research in higher education institutions. The subsequent sections describe the methodology, including the approach to data collection and analysis, and report and discuss the findings. Finally, conclusions and recommendations for practice and further research are outlined.

\section{Literature review}

\section{Knowledge management processes in higher education}

Despite the fact that knowledge lies at the heart of the role of universities, research into knowledge management in higher education is relatively recent. Rowley (2000) and Kidwell et al. (2000) were some of the first authors to label universities as knowledge creating institutions, and to view them as being in the knowledge business. Thereafter, successful KM practices from the private sector were replicated in HEIs, but without any real understanding of KM concepts and benefits and focussing only on the use of IT to implement and support KM (Cranfield and Taylor 2008; Alexandropoulou et al. 2009; Mavodza and Ngulube 2012). Several commentators have suggested that universities need to adopt a more comprehensive approach to KM and to capitalise on the potentially significant benefits of adopting a strategic approach to knowledge management practices, in the arenas of k-creation, k-sharing and k-transfer, and thereby to support their mission (research, teaching and service to society), (Rowley 2000; Alexandropoulou et al. 2009; Ramachandran et al. 2009; Fullwood et al. 2013). More specifically, absence of a KM strategy and an institution-wide approach to KM was considered to be one of the barriers to the implementation KM in HEIs (Cranfield and Taylor 2008; Laal 2011).

Previous research into the KM processes associated with k-creation, k-sharing and k-transfer is summarised below.

Knowledge creation aims at increasing knowledge through interactions between explicit (documented) and tacit (embedded in people) knowledge in individual human minds, such as doctoral training, scientific discovery and codified knowledge (Nonaka 1994; Rowley 2000; Alexandropoulou et al. 2009). KC is also associated with researchers' scientific socialization, the combination of scientific findings, and publishing the findings of research (Dorri and Talebnejod 2008 cited in Siadat 2012). Despite the acknowledgement that universities should be regarded as knowledge creating institutions on account of their heavy involvement in research, only a few studies have investigated the knowledge creation role of universities. These studies reveal the need to enhance the creative environment, using both soft (personalisation) and hard (technology) strategies (Tian et al. 2009), organizational culture and supportive social networks (social capital) (Siadat et al. 2012).

Knowledge Sharing is an integral part of higher education institutions. The number of seminars, conferences and publications that academics are involved in exceeds the level of involvement in other professions, suggesting that academics have a readiness to share knowledge (Cheng et al. 2009). In other words, an implicit knowledge sharing culture exists which helps universities to strengthen their research and teaching activities, but, that culture is individualistic in nature and to some extent self-serving (Fullwood et al. 2013; Goh and Sandhu 2013). Despite the existence and 
importance of knowledge sharing, "knowledge hoarding" is also prevalent as academics seek to protect their most valuable career progression asset, knowledge (Cheng et al. 2009; Fullwood et al. 2013; Goh and Sandhu 2013). In spite of the significant interest in KS research in the sector, no study has explored KS activities in HE. Most studies have explored the determining factors of KS in HEIs (Cheng et al. 2009; Fullwood et al. 2013).

Knowledge transfer. The focus on 'third mission' or 'third stream activity' to support economic development has led to many studies on knowledge transfer from universities to industry, the public sector and the public in general, by a variety of means, including disclosures, patenting, licensing, job creation through spin-off companies, contracts and consultancy research, continuous professional development (CPD), and access to facilities and equipment (Alexandropoulou et al. 2009; Mustapha 2010; Rossi and Rosli 2015; Sengupta and Ray 2017; Fuller et al. 2017; Cervantes 2017). Furthermore, different KT activities are viewed as 'soft' and 'hard' where 'soft' relates to public lectures and consulting (practiced in traditional universities) and 'hard' entails licensing or spin-off creation in universities engaged in a greater level of third-stream activities (Rossi and Rosli 2015; Fuller et al. 2017). KT also corresponds with the 'Triple Helix' concept of bringing together academia, industry and government (Etzkowitz et al. 2000; Mustapha 2010) for economic benefit.

Despite the acknowledgement that there is a need to manage knowledge effectively in higher education, the body of research into the implementation of KM in HEIs is limited. Rivera and Rivera (2016) do explore the processes of knowledge creation, storage, transfer and application (not knowledge sharing), but their primary focus is on the enablers of knowledge management processes. Ramachandran et al. (2009) studied the six knowledge management processes, but the only overlap between this study and the current study is in the area of knowledge creation. There are other relevant studies but they have investigated only one or two KM processes (Cheng et al. 2009; Tian et al. 2009; Siadat et al. 2012; Fullwood et al. 2013; Goh and Sandhu 2013; Sengupta and Ray 2017). However, no study has developed models mapping the three sets of KM processes relating to k-creation, $\mathrm{k}$-sharing and $\mathrm{k}$-transfer, in HEIs, in one study.

In addition, the majority of studies have been conducted in Malaysia (Cheng et al. 2009; Ramachandran et al. 2009; Goh and Sandhu 2013) and the UK (Cranfield and Taylor 2008; Fullwood et al. 2013; Rossi and Rosli 2015; Fuller et al. 2017; Sengupta and Ray, 2017), with very little previous research reporting on the sub-Saharan African region (Mavodza and Ngulube 2012). It is important to study the KM processes in the HE sector for more evidence from other regions to see whether the patterns are similar or different, and whether a common model could emerge for developed and developing countries.

To conclude, whilst there is ample evidence that processes associated with $\mathrm{KM}$ - knowledge creation, sharing and transfer are being practiced in HEIs (Ramachandran et al. 2009; Tian et al. 2009; Fullwood et al. 2013; Sengupta and Ray, 2017), no one has conducted a comparative study of two different countries.

Hence, the purpose of this study is to address this gap in the literature and contribute to the existing body of knowledge on KM in the higher education sector, through a comparative research study based in two different countries, one with a small and developing higher education sector and other 
with a relatively well-developed higher education sector, Mauritius and South Africa. This article thereby, builds a profile of the similarities and differences between the two countries, and develops models of KM processes. This comparison acts as a basis for recommendations for improving research practices leading to innovation in the less developed country.

\section{Methodology}

\subsection{Research Context}

Mauritius and South Africa, two of the most competitive economies in the sub-Saharan region, were chosen as the case study sites for this article. The Global Competitiveness Report (2018), ranks Mauritius as $49^{\text {th }}$ and South Africa as $67^{\text {th }}$ out of 140 countries. However, on innovation capability, South Africa scores higher $\left(46^{\text {th }}\right)$ than Mauritius $\left(62^{\text {nd }}\right)$. On the other hand, according to the Times Higher Education World University Ranking, nine South African universities are amongst the Top 30 African Universities, including the top four universities, whereas none of the Mauritian universities feature in the list. One of South Africa's universities appears in the top 200 of the worldwide rankings, and South Africa is the only country in Africa with a university in the top 500 .

Compared to Mauritius, the higher education sector in South Africa is relatively large and welldeveloped. For a population of about 57.5 million, according to the Council of Higher Education website (http://www.che.ac.za/focus_areas/higher_education_data/2013/overview) it encompasses 26 public institutions, which include eleven traditional universities, six universities of technology, eight regional "comprehensive" universities resulting from restructuring existing universities and polytechnics and one Health Sciences University. According to 2015 statistics, the higher education sector also includes 124 private higher education institutions.

The higher education sector in Mauritius is relatively small and evolving. The country has more than sixty higher education institutions, including ten public HEI's (http://tec.intnet.mu/overview) for a relatively small population of about 1.3 million. Most of the private HEI's are small, low quality institutions which cannot be regarded as 'universities' (Cloete and Maassen in: Muller et al. 2017: 101) and are mostly local branches of overseas institutions and/or affiliated with overseas institutions from, for example, Australia, India, South Africa, and the UK.

As Mauritius aspires to become a knowledge hub and a regional centre of excellence for higher education, it is imperative that the quality of HEIs and their research output is on par with the regional leaders. Hence a comparative study of two countries who are at different stages in the development of their university sector was conducted.

\subsection{Research approach}

This study used interviews with key informants in thirteen HEI's of Mauritius and South Africa (seven HEI's in Mauritius and six HEI's in South Africa) to gather insights into the knowledge management strategies and processes: knowledge creation, sharing and transfer. Since knowledge management is a relatively new concept for HEIs in sub-Saharan African countries, including Mauritius and South Africa, qualitative research using semi-structured interviews that seeks to 
generate in-depth insights was deemed to be appropriate (Saunders et al. 2016). Furthermore, an interpretivist stance that is inductive in nature was adopted in this study.

An interview schedule was designed and piloted through meetings with three senior academics with significant experience in research and research management, including two Professors (former deans) and one head of institution.

Face-to-face interviews were conducted in Mauritius with eleven senior managers and academics involved in research and/or research management from four public universities and three private HEIs. In South Africa, Skype interviews were conducted with eight senior managers involved in research and/or research and innovation management from six public universities; these universities are amongst the top 30 universities in Africa (Table 1).

Table 1: Participant Profile

\begin{tabular}{|c|c|c|c|}
\hline $\begin{array}{l}\text { Country/ } \\
\text { Type of } \\
\text { Institutions }\end{array}$ & $\begin{array}{l}\text { Institution } \\
\text { Number }\end{array}$ & Participants & Brief description of participants \\
\hline \multirow{4}{*}{$\begin{array}{l}\text { Mauritius } \\
\text { Public } \\
\text { Universities }\end{array}$} & 1 & $\begin{array}{l}\text { M-A1 } \\
\text { M-A2 } \\
\text { M-A3 }\end{array}$ & $\begin{array}{l}\text { Three senior academics and researchers at } \\
\text { Associate Professor and Professor level, former } \\
\text { Heads of Departments and Heads of Faculties }\end{array}$ \\
\hline & 2 & $\begin{array}{l}\text { M-B1 } \\
\text { M-B2 } \\
\text { M-B3 }\end{array}$ & $\begin{array}{l}\text { Head of Institution } \\
\text { Head of Faculty } \\
\text { Academic researching in KM }\end{array}$ \\
\hline & 3 & $\mathrm{M}-\mathrm{C}$ & Head of Faculty \\
\hline & 4 & M-D & Head of Institution \\
\hline \multirow{3}{*}{$\begin{array}{l}\text { Mauritius } \\
\text { Private } \\
\text { HEIs }\end{array}$} & 5 & M-E & Head of Academics \\
\hline & 6 & $\mathrm{M}-\mathrm{F}$ & Head of Institution \\
\hline & 7 & $\mathrm{M}-\mathrm{G}$ & Head of Academics \\
\hline \multirow{6}{*}{$\begin{array}{l}\text { South } \\
\text { Africa } \\
\text { Public } \\
\text { Universities }\end{array}$} & 1 & SA-A & $\begin{array}{l}\text { Deputy Vice-Chancellor: Research, Innovation } \\
\text { and Technology }\end{array}$ \\
\hline & 2 & $\begin{array}{l}\text { SA-B1 } \\
\text { SA-B2 }\end{array}$ & $\begin{array}{l}\text { Executive Director Research and Innovation } \\
\text { Senior Director, Postgraduate School }\end{array}$ \\
\hline & 3 & $\begin{array}{l}\text { SA-C1 } \\
\text { SA-C2 }\end{array}$ & $\begin{array}{l}\text { Director, Innovation Office } \\
\text { Director, Research Capacity Development }\end{array}$ \\
\hline & 4 & SA-D & $\begin{array}{l}\text { Pro-VC Innovation, Commercialisation and } \\
\text { Entrepreneurship }\end{array}$ \\
\hline & 5 & SA-E & Assistant Director Research Data Management \\
\hline & 6 & $\mathrm{SA}-\mathrm{F}$ & Director of E-Research \\
\hline
\end{tabular}

Potential participants were contacted in order to obtain approval to interview them or their senior colleague(s). Prior to each interview, the researcher provided the interviewee with information on the study, the interview guide and knowledge management terminology and definitions to facilitate discussion during the interview. Permission to record each interview was obtained through a consent form. Participation in the study was voluntary and interviewees were informed that interviews and any documents provided during and after the interview were confidential; 
interviewees were free to decline to answer any questions or to withdraw from the interview at any time.

The interviews took between 45 minutes and an hour. Interviews were transcribed using Microsoft Word. Interview transcripts were reviewed, leading to data reduction. Next, summary notes were made, and thematic analysis was undertaken by identifying patterns and themes in the collected study data (Miles and Huberman 1994). The analysis was guided by the themes in the interview schedule, but was not restricted to them. This was supported by concept maps, a visualization technique, to create models, which facilitated comparison between the two countries (Kinchin and Streatfield 2010).

\section{Findings}

\subsection{Knowledge Management Strategy}

Even though participants were familiar with the term 'knowledge management', none of the participating higher education institutions, both in Mauritius and South Africa, had an explicit KM strategy, under the title "knowledge management strategy" in their institutional strategic plans.

There is no explicit KM strategy. (M-A3)

No, we don't have a KM strategy as such on paper, but we practice it. (M-E)

We don't have a knowledge management strategy or policy, what we have is an Intellectual Property Policy which talks about commercialisation and we have a policy on research project processing. But we don't have a specific strategy on KM. (SA-C1)

However, South African HEIs did have strategic plans on research, innovation and community engagement, and numerous other related documents, policies and strategies to promote: knowledge creation (research strategy and policy, data management policy, research data management policy, information management strategy and policy); knowledge sharing (open access policy); and, knowledge transfer (policy on research project processing, contracts management, intellectual property policy). Interviewees felt that these could be clustered under knowledge management. In contrast, of Mauritian HEIs, only three of the seven HEIs that participated in the study had strategic plans.

We have an information management strategy, which covers knowledge creation, sharing and transfer. It's a new national policy to share databases ... and we have an information management policy which is being developed right now. We have a research policy and we also have a strategic document on research, innovation and community engagement, I think all of that together will constitute knowledge management. (SA-A)

\subsection{Knowledge Management Processes}

All participating HEIs of Mauritius and South Africa were involved in knowledge creation and acquisition, knowledge sharing, and knowledge transfer. The KM processes adopted in the two 
countries were similar, although there were some important differences, as elaborated in this section and as summarised in Figure 1.

Insert Figure 1 here

\subsubsection{Knowledge Creation}

Knowledge creation was not regarded as being restricted to research. Knowledge was also regarded as being created through teaching and learning, organizational documentation and knowledge acquisition from external sources. There were two differences between the two countries. Whereas interviewees from Mauritius discuss consultancies, interviewees from South Africa mentioned contract research, and also reported on knowledge creation through social engagement and social investment with the wider community.

Insert Figure 2 here

The remainder of this section comments on the $\mathrm{KC}$ processes as listed in Figure 2. Knowledge creation through teaching and learning had different connotations in the two countries. In Mauritius, it entailed knowledge creation during curriculum development and preparation of lectures, whereas, in South Africa, the participants focussed on the role of teaching and learning in leading to best practice, and ensuing innovation in teaching.

When people talk about creation of knowledge [they] tend to restrict [it] to research. But to my mind you also create lots of knowledge during your teaching and learning activities. $(M-A 2)$

If we look at most universities, they sit on three main pillars, which are, teaching and learning, research and the third one, I would term 'community engagement'. On the teaching and learning side knowledge creation comes in terms of best practices and new innovation in teaching, and the universities are pretty good in that regard. (SA-D)

As reported, in both countries knowledge creation by research was through academics and students undertaking research. Additionally, in South Africa research undertaken by research groups/ research entities and through national and international collaboration leads to knowledge creation in the form of research publications in high-ranked journals.

Knowledge is created through research that the lecturers do, or if they supervise students. $(M-B 1)$

New knowledge is produced from research through our research entities. In total we have six research entities where new knowledge is produced and where post graduate research is carried out. (SA-A)

Knowledge creation through organisational documentation, such as, policies, strategies, charters, and notes of meetings, was also mentioned by interviewees from both countries. 
The other knowledge in [the] university would be [...] a range of rules and regulations within the university, academic policies and procedures, hand books and staff guide, telling new staff what they have to do and what we expect of them. (M-F)

Also through documentation, for example, I could go back and find all of the information about various committees, the charters, the minutes of meetings, and the recordings of some meetings. (SA-B1)

Knowledge creation through acquisition from external sources was also reported in both countries, although there were subtle differences in the sources cited. In South Africa, it entailed acquisition of knowledge from national and international visitors, whereas, in Mauritius, the focus was on KC from qualified staff, books, journals, the internet, meetings, visiting experts, international partnerships and attending seminars, workshops and conferences.

Our staff acquire knowledge through books, through internet sites or through their own experience. Knowledge is also acquired through our internal and external committees ( $M$ A1). From international conferences, workshops and committees (M-B1). From our international academic partners (M-E).

The university is a place where lot of people come and go from the private sector, the government sector, international visitors, so they come and they share, so that's all adding to the body of knowledge. (SA-B1)

The Mauritius participants referred to KC through 'consultancies' with public bodies, private companies and non-governmental organisations locally, regionally and internationally, whilst in South Africa they referred to knowledge creation through 'contract research' with the public and private sector as well as social engagement and social investment with the community.

We create knowledge through our consultancies, when we interact with other people. (MA1)

We also have our staff involved in research, that could be just personal or individual projects that they pursue as part of their own research interest or contract research. (SAC2)

\subsubsection{Knowledge Sharing}

Similar processes are adopted for knowledge sharing in Mauritius and South Africa, such as internal meetings, publications, collaborative platforms, seminars and conferences. The one exception, the use of media, was only reported by South African participants.

Insert Figure 3 here

The remainder of this section comments on the $\mathrm{KC}$ processes as listed in Figure 3. Although both groups reported on the importance of internal meetings for knowledge sharing, the focus differed. In 
Mauritius, the focus was on curriculum development, while in South Africa it was on sharing of knowledge between supervisors and their research groups.

Within departments and subject groups, we have both formal and informal meetings, to talk not necessarily about new knowledge but about the knowledge we are sharing with students. We have curriculum meetings and module meetings and if the module has lots of students then it is shared by a number of staff. $(M-F)$.

The most sharing that happens is probably between a supervisor and his or her research group. So, at this level, there is better sharing than there is perhaps at the institutional level or even at the faculty level. (SA-C2)

Knowledge sharing through publications in Mauritius entails publication, mainly in the university research journal, which has a relatively low impact factor ranking, whilst in South Africa it involves publication in peer-reviewed and high impact factor research journals, research reports, newsletter and annual reports.

The setting-up of the Research Journal in 1998 contributed to the sharing of knowledge at the university, which has been available online since 2001 to facilitate dissemination of the research findings to a wide audience. (M-A2)

We adopt an open source approach as far as possible, obviously academics will share the publications through the normal, open and the regular journal process. We have our regular reports by the research entities, shared amongst the academics.... We also share infrastructure facilities by as far as possible making infrastructure available to some groups who do not attract extensive equipment. They are all geared towards a bigger knowledge management system, [including] both creation as well as the recording and the sharing of knowledge. (SA-A)

South African participants reported on the use of emails and websites, alongside research repositories, as collaborative platforms for knowledge sharing. Only two participants from private HEIs in Mauritius mentioned research repositories as collaborative platforms, and even though emails are widely used in Mauritian HEIs, they were not reported as being a knowledge sharing mechanism. Participants from both countries reported on knowledge sharing through seminars and conferences, although, in Mauritius these seemed to occur on an annual/ad hoc basis, whilst in South Africa, regular public, professorial and seminal lectures are organised at various institutional levels.

The research week is a major forum/ platform for sharing. (M-A2)

We have an annual conference here and teaching and learning conference, where we share ideas with the public as well. (M-F)

People mostly use email, and some use the data management project that we are running for five pilot research groups in different disciplines. The research groups upload research data on to a document management system, where they also collaborate. So, it's a very good collaborative space for them. As this system has not been rolled out to the rest of the 
university yet, so most people would still communicate by email and during workshops on campus. (SA-E)

There are mechanisms where people can share information and some of them obviously are workshops, seminars and public lectures that are regularly held within disciplines. These are generally vehicles for sharing of knowledge within the institutions. (SA-D)

We have regular seminars, particularly among students, the post graduate students have a seminar every quarter. Most departments organise these. We have public lectures, professorial lectures (whenever there is an overseas Prof on the Campus, they give a public lecture which is attended by staff and students) or seminal (influential) lectures by guest speakers. Seminars on specific areas; the last one that we had was on engagement. (SAC1)

We provide a collaborative platform to researchers, to help them to build collaborations with peers or with research partners in other institutions. (SA-F)

Finally, South African HEIs also use media, such as, newspapers and social media to share their knowledge.

The institutions use different types of media. They have annual reports, they may have newsletters, and websites. Those are the media through which knowledge sharing takes place. $(S A-D)$

\subsubsection{Knowledge Transfer}

There was a shared view that knowledge transfer included: transfer of knowledge to students in the classroom, and training them to join the workforce, publication of research outputs, and community engagement, but there are many differences in the approaches adopted to KT between the two countries (see Figure 4).

\section{Insert Figure 4 here}

For example, in South Africa, community engagement through dissemination of research outputs in schools and to local community is institutionalised through the South African Agency for Science and Technology Advancement (SAASTA), an arm of the National Research Foundation (NRF). On the other hand, only one interviewee from Mauritius mentioned community engagement.

The students have to be involved with society, so that they know exactly what the society needs and how they can help. It's like service to the society. This will build their values. When we collaborate with industry, and with NGOs we will learn more and we will know how to help. (M-B3)

At a more national level, the National Research Foundation (NRF) has an arm called the South African Agency for Science and Technology Advancement (SAASTA), and that 
particular sub-division of the NRF is actually responsible for research dissemination to non-scientific communities. (SA-C2)

As also mentioned in the previous section on knowledge creation, a few public Mauritian HEIs are involved in transferring knowledge through consultancies, and the remaining HEIs are involved in organising tailor-made courses and continuous professional development (CPDs) programmes for the public and private sectors. On the contrary, researchers from top South African universities are engaged with industry through undertaking contract research which is facilitated through their dedicated technology transfer offices.

We interact with industry, transferring knowledge to industry through consultancy to different stakeholders, government or industry. (M-A1)

We are involved in producing tailor made training programmes for both the private and the public sector. $(M-D)$

The policies of the government support our researchers having a legitimate content that can be transferred. The researchers, through the TTO, can transfer their research knowledge to the private sector as contract research. We also identify potential ideas from their research and try to pitch them with some companies using the tech transfer process. $(S A-C 1)$

South African universities are also engaged in knowledge transfer through popular media newspapers and twitter, which was not reported by any interviewees in Mauritius. On the contrary, Mauritian interviewees reported on transferring knowledge by participating in seminars and conferences and through websites, in the form of annual reports and newsletters. These were reported as 'knowledge sharing' mechanisms by South African participants. In Mauritius, participating in external meetings was also considered to be a means of knowledge transfer; this was not reported by South African participants.

We have our annual reports and newsletters, which are sometimes posted on websites, but we need another mechanism to transfer that knowledge in layman's language. (M-A1)

We also participate in workshops, advisory committees and brainstorming sessions. Whenever we are invited, we go and participate and share our knowledge with them. (ME)

At the university, knowledge transfer falls under the portfolio 'research and engagement', and engagement, involves not only outreach and community work in schools and the local community, but it also involves engagement with industry and with the popular media. We have a very good relationship with our local newspapers and it's become a more conscious effort to inform the community about what the universities are researching and more popularisation of science. (SA-C2)

Furthermore, South African participants reported on the presence of a "research office or technology transfer office or research and engagement office" in their universities, which 
facilitates knowledge transfer from universities to outside partners, as well as providing support services for patenting and commercialisation of their research outputs. On the other hand, interviewees from Mauritius commented on the absence of a dedicated knowledge transfer strategy.

We don't have an office of Knowledge Transfer/ Technology Transfer, but under my office, I tap the knowledge of the institution, as I know where it exists. (M-B1)

In my view the end product of knowledge generation shouldn't be an article, I mean that's fine, but one must tell companies out there how to do things better. If the researcher wants to go further towards patenting, the Tech Transfer Office facilitates it. (SA-A)

Yes, we have this group in the Research Office, the Technology Transfer Office, so they do a lot of that work (Knowledge transfer). You called it KTO, but here we call them TTO and they are also responsible for patenting. Then there is also the traditional publishing route and media. We put a lot on twitter. (SA-F)

\section{Discussion}

First, the study found that participants from both Mauritius and South Africa were conversant with the term, knowledge management, but their institutions did not have an explicit KM strategy as also reported in previous work by Cranfield and Taylor (2008) and Trivella and Dimitrios (2015).

Nevertheless, participating top-ranking South African universities had numerous strategies and policies to promote knowledge creation (research strategy and policy, data management policy, research data management policy, information management strategy and policy), knowledge sharing (open access policy) and knowledge transfer (policy on research project processing, contracts management, intellectual property policy). Participants felt that together these could constitute a KM strategy. On the other hand, even though Mauritius aspires to be a 'Knowledge Hub and a Centre of Higher Learning' and has a well-articulated national policy and a clear role for higher education in development not all HEIs had strategic plans or policy documents. Participants were of the view that policy directions from government were necessary in order to encourage and steer research productivity in universities, as is the case in South Africa and in other developed countries (New Zealand, Hong Kong, Australia and UK). A study in Japan also revealed the need to enhance the creative environment in academia, using both soft (personalisation) and hard (technology) strategies (Tian et al. 2009).

Secondly, the study confirmed that all participating HEIs in Mauritius and South Africa are involved in all three of knowledge creation and acquisition, knowledge sharing and knowledge transfer. Most past studies have reported on one or two KM processes practiced in HE context (Cheng et al. 2009; Tian et al. 2009; Siadat et al. 2012; Fullwood et al. 2013; Goh and Sandhu 2013; Sengupta and Ray 2017). Only one previous study identified evidence of six KM processes in HEIs (creation, capture, organisation, storage, dissemination, and application) (Ramachandran et al. 2009). However, no previous studies on KM in higher education have explored and developed models mapping all three sets of KM processes (k-creation, $\mathrm{k}$-sharing and $\mathrm{k}$-transfer) in one study. 
Previous research on knowledge management in universities has focused mainly on academics in a single country, with a majority in Malaysia followed by the UK. This research contributes by exploring the understanding of senior managers and academics involved in research/and research management and comparing the three KM processes in two countries, Mauritius and South Africa, in the sub-Saharan region, where very few studies have been carried in the past.

In addition, the KM processes adopted in the two countries had a lot in common, but there were some important differences. Similarities in knowledge creation, knowledge sharing, and knowledge transfer in the two countries reflect adherence to the expected roles and mandates of universities (teaching, research and service to society). Similar k-creation processes identified were: research, teaching and learning, organizational documentation and acquisition from external sources. For k-sharing, similar processes were: internal meetings, publications, collaborative platforms, seminars and conferences. And, for k-transfer: through students in classroom and training them to join the workforce, publications of research outputs in journals and engaging with community, were in evidence in universities in both countries. Hence, it is evident that lack of an explicit KM strategy does not prevent HEIs from creating, sharing and transferring knowledge. This is most likely because these processes contribute to delivering on the established roles of modern universities.

The differences between Mauritius and South Africa are, however, important. For example, under $\mathrm{KC}$, South African participants reported on knowledge creation through social engagement and social investment, together with the use of media (newspaper, Twitter) for knowledge sharing and transfer. Consultancy in Mauritius versus contract research in South Africa as means of knowledge creation and knowledge transfer was a major difference reported in the KM practice of the two countries. This is consistent with the "soft" and "hard" KT practices reported in previous studies (Fuller et al. 2017), wherein "soft KT" are practiced in traditional universities and "hard KT" in universities that have a stronger third-stream portfolio.

In South Africa, universities have been supported and mandated to engage with communities and businesses, through institutionalised structures, such as, the South African Agency for Science and Technology Advancement (SAASTA) and National Research Foundation (NRF) at national level and Technology Transfer Offices (TTOs) and research offices at institutional level. In contrast, in Mauritius, in the absence of dedicated office for KT, in addition to consultancies, participating in seminars and conferences and attending external meetings were considered as means of transferring knowledge. This is consistent with past studies on HEIs, which label universities as 'low research intensive or high research intensive', 'teaching-only or research-led or entrepreneurial' universities (Hewitt-Dundas 2012; Rossi and Rosli 2015; Fuller et al. 2017; Fussy 2017). Hence the differences in KT practices could be attributed to the fact that the HE sectors in the two countries are at different stages of the developmental cycle, Mauritius with mainly teaching higher education institutions and South Africa with research-led universities supported by policies to encourage research productivity and its application.

\section{Conclusion and recommendations}

The study concludes that the three KM processes $-\mathrm{KC}, \mathrm{KS}$ and $\mathrm{KT}$, which are closely linked to the three missions of contemporary HEIs (teaching, research and service to society), are being 
practiced in both Mauritius and South Africa, despite the absence of a KM strategy. The three KM processes adopted in the two countries had a lot of similarity with only a few differences. More similarities in practice were found in the areas of knowledge creation and sharing, with the most evident divergence in the practices of knowledge transfer. These similarities and differences between the two countries correspond with the developmental stages of the HE sectors in Mauritius and South Africa, one with mainly teaching institutions and the other with a much stronger research focus.

This article also contributes by building a profile of the similarities and differences between the two countries, and develops models of KM processes - knowledge creation, knowledge sharing and knowledge transfer. This comparison acts as a basis for recommendations for improved knowledge management practices, which have the potential to support innovation in the less developed country, and potentially in other developing countries.

It is recommended that policy makers need to provide policy direction to enhance research and innovation in emerging HE sectors, such as, Mauritius and other countries in the region. It is also important that they develop a well-defined KM strategy and a roadmap to enhance KC, KS and $\mathrm{KT}$ in their universities. Secondly, there is a need to enhance the levels of investment in R\&D. The Science, Technology and Innovation Strategy for Africa 2024, published by the African Union, suggests that all African countries need to increase their investment in R\&D to at least $1 \%$ of their GDP. These targeted investments should be earmarked for development of research skills and capacity, infrastructure (well-equipped laboratories, research repositories, Knowledge Transfer Office/ Technology Transfer Office), strategically selected partnerships with business and public sector organisations, to increase knowledge creation, sharing and transfer.

This study has demonstrated that the knowledge management theoretical lens provides interesting insights into the processes in universities that support their core missions in research, teaching and knowledge transfer. Accordingly, there is considerable scope for further research into KM processes and their contribution to excellence in higher education. Further comparative studies would be useful in building a wider international picture of KM processes in universities. In addition, longitudinal studies might yield insights into how KM processes change as countries, particularly developing countries, invest in and evolve their higher education sector. Other potential lines of enquiry are: within country studies that examine the differences in KM processes between research-focussed and teaching-focussed universities; and, studies that explore the perceptions of a wider range of stakeholder groups, such as academics, researchers and public and private sector university partners.

\section{References}

African Union. 2014. The Science, Technology and Innovation Strategy for Africa (STISA-2024). Accessed December 13, 2018. https://au.int/sites/default/files/newsevents/workingdocuments/33178-wd-stisa-english_final.pdf

Alexandropoulou, D. A., V. A. Angelis, and M. Mavri. 2009. "Knowledge management and higher education: present state and future trends." International Journal of Knowledge and Learning 5(1): 96-106. 
Cervantes, M. 2017. "Higher Education Institutions in the Knowledge Triangle." Foresight and STI Governance 11 (2): 27 - 42.

Cheng, M., J.S. Ho, and P.M. Lau. 2009. "Knowledge sharing in academic institutions : a study of Multimedia University Malaysia.” Electronic Journal of Knowledge Management 7 (3): 313 324.

Cloete, N. and P. Maassen. 2017. Roles of universities and the African context. In: Muller, J., P. Cloete, and F. Van Schalkwyk. (eds), Castells in Africa - Universities and Development: Cape Town: African Minds: 95-112.

Cortez, E.-M., J. Britz, and P. Mullins. 2011. "Applying knowledge management strategies to economic development in sub-Saharan Africa." Inkanyiso: Journal of Humanities and Social Sciences 3 (2): 140-147.

Cranfield, D. J. and J. Taylor. 2008. "Knowledge management and higher education: a UK case study." Electronic Journal of Knowledge Management 6 (2): 85-100.

Dorri, B. and Talebnejod, A. 2008. "Investigating the situation of the techniques of knowledge creation in the univerisities related to the Ministry of Education, Research and Information Technology." Quarterly of Research in Higher Education 49.

Etzkowitz, H. and L. Leydesdorff. 2000. "The dynamics of innovation: from National Systems and "Mode 2" to a Triple Helix of university-industry-government relations." Research Policy 29 (2): 109-123.

Fuller, D., M. Beynon, and D. Pickernell. 2017. "Indexing third stream activities in UK universities: exploring the entrepreneurial/enterprising university." Studies in Higher Education, DOI: 10.1080/03075079.2017.1339029

Fullwood, R., J. Rowley, and R. Delbridge. 2013. "Knowledge sharing amongst academics in UK universities." Journal of Knowledge Management 17 (1): 123-136.

Fussy, D. S. 2017. "Policy directions for promoting university research in Tanzania." Studies in Higher Education, DOI: 10.1080/03075079.2016.1266611

Goh, S.K. and M.S. Sandhu. 2013. "Knowledge sharing among Malaysian academics: influence of affective commitment and trust." Electronic Journal of Knowledge Management 11 (1): $38-48$.

Hewitt-Dundas, N. 2012. "Research intensity and knowledge transfer activity in UK universities." Research Policy 41 (2): 262-275.

Kidwell, J.J., K.M. Vander Linde, and S.L. Johnson. 2000. "Applying corporate knowledge management practices in higher education." Educause Quarterly 23 (4): 28-33.

Kinchin, I.M. and D. Streatfield. 2010. "Using Concept Mapping to Enhance the Research Interview." International Journal of Qualitative Methods 9 (1): 52-68.

Laal, M. 2011. "Knowledge management in higher education." Procedia Computer Science 3: 544-549.

Mavodza, J. and P. Ngulube. 2012. "Knowledge management practices at an institution of higher learning." South African Journal of Information Management 14 (1): 1-8.

Miles, M. and A. Huberman, A. 1994. Qualitative Data Analysis: An Expanded Sourcebook, Sage, Beverly Hills, CA

Mustapha, R. B. 2010. "Proposing a New Model of Knowledge Innovation for Research University Based on Entrepreneurial Paradigm.” Educare: International Journal for Educational Studies 2 (2): 111-130.

Nonaka, I. 1994. "Dynamic theory knowledge of organizational creation." Journal of Organization Science 5 (1): 14-37. 
OECD. 1997. National Innovation Systems, Organisation for Economic Cooperation and Development (OECD), Paris. https://www.oecd.org/science/inno/2101733.pdf

Philpott, K., L. Dooley, C. O'Reilly and G. Lupton. 2011. "The entrepreneurial university: Examining the underlying academic tensions." Technovation 31 (4): 161-170.

Ramachandran, S.D., S.C. Chong, and H. Ismail. 2009. "The practice of knowledge management processes: a comparative study of public and private higher education institutions in Malaysia." Vine 39 (3): 203-222.

Rinaldi, C., A. Cavicchi, F. Spigarelli, L. Lacchè, and A. Rubens. 2018. "Universities and smart specialisation strategy: From third mission to sustainable development co-creation." International Journal of Sustainability in Higher Education 19 (1): 67-84.

Rivera, G. and I. Rivera. 2016. "Design, measurement and analysis of a knowledge management model in the context of a Mexican university." Innovar Open Access 26 (59): 21-34.

Rossi, F and A. Rosli. 2014. "Indicators of university-industry knowledge transfer performance and their implication for universities: evidence from the United Kingdom." Studies in Higher Education, 40 (10): 1970-1991.

Rowley, J. 2000. "Is higher education ready for knowledge management?” International Journal of Educational Management 14 (7): 325-333.

Saunders, M., P. Lewis, and A. Thornhill. 2016. Research Methods for Business Students, $7^{\text {th }}$ ed., Pearson, England.

Sengupta, A. and A. S. Ray. 2017. "University research and knowledge transfer: A dynamic view of ambidexterity in British universities." Research Policy 46 (5): 881-897.

Siadat, S.A., R. Hoveida, M. Abbaszadeh and L. Moghtadaie 2012. "Knowledge creation in universities and some related factors." Journal of Management Development 31 (8): 845-872.

Stamou, A. 2017. "Knowledge management in doctoral education toward knowledge economy." International Journal of Educational Management 31 (3): 320-331.

Tian, J., Y. Nakamori, and A.P. Wierzbicki. 2009. "Knowledge management and knowledge creation in academia: a study based on surveys in a Japanese research university." Journal of Knowledge Management 13 (2): 76-92.

Trivella, L. and N.K. Dimitrios. 2015. "Knowledge Management Strategy within the Higher Education. The case of Greece." Procedia - Social and Behavioral Sciences, 175: 488-495.

UNESCO. 2010. Trends in Tertiary Education: Sub-Saharan Africa. UNESCO. Accessed February 15, 2016. http://www.uis.unesco.org/Library/Documents/fs 10-trends-tertiaryeducation-sub-saharan-africa-2010-en.pdf

World Economic Forum. 2018. The global competitiveness report. Geneva: World Economic Forum. 
Figure 1: Summary of Knowledge Management processes in HEIs of Mauritius and South Africa
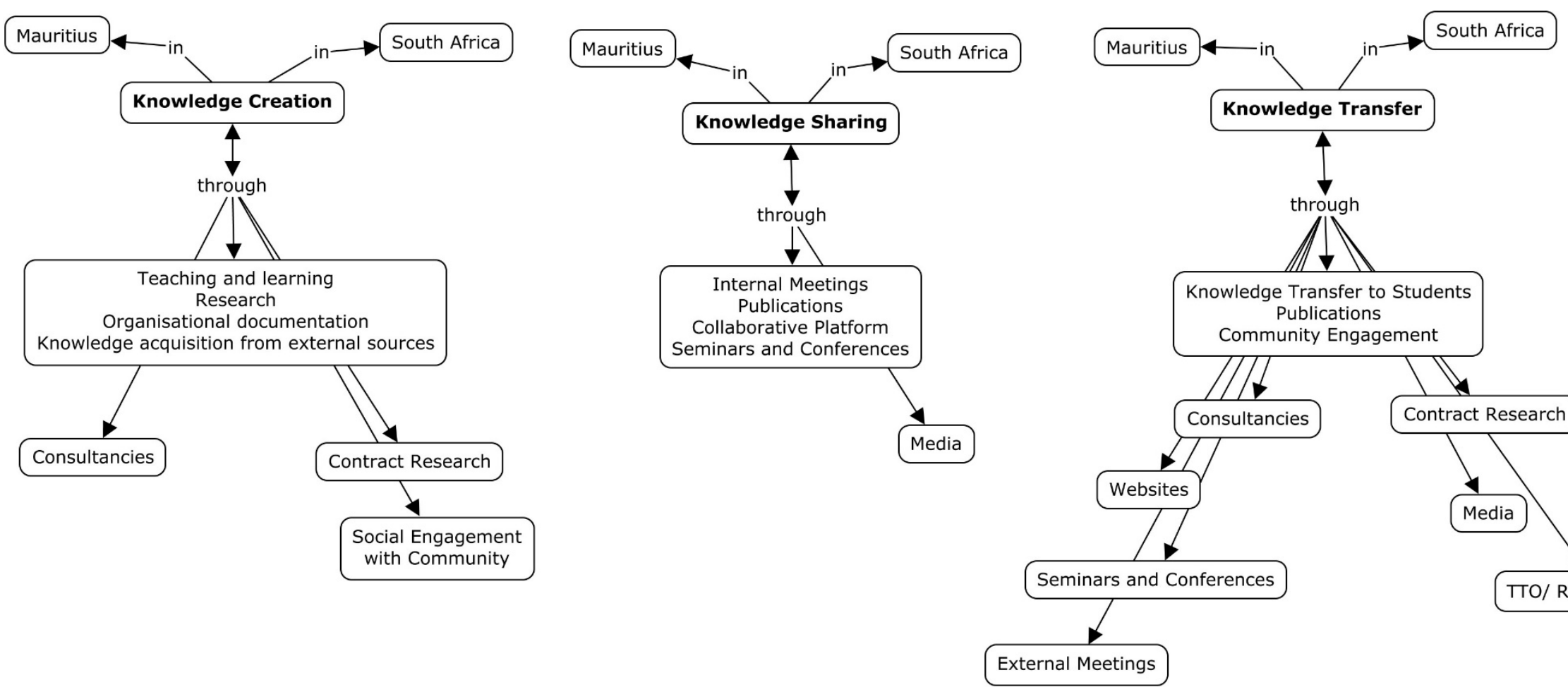
Figure 2: Knowledge creation processes in HEIs of Mauritius and South Africa

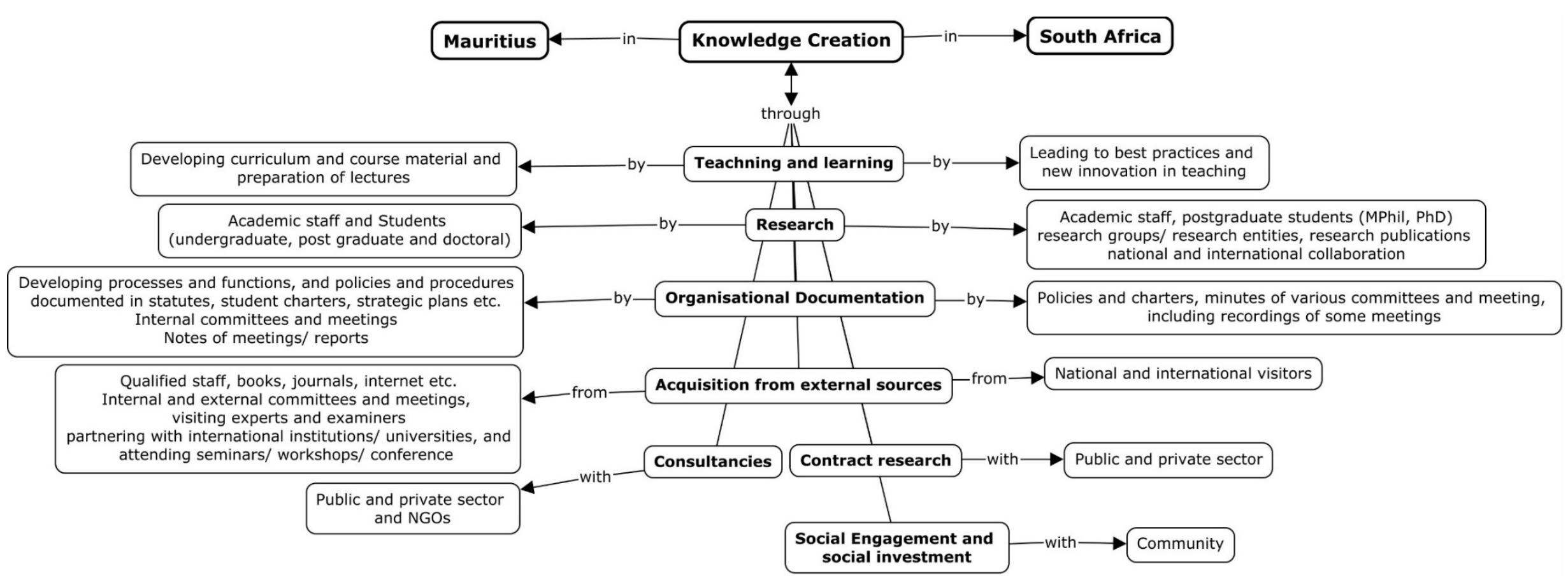




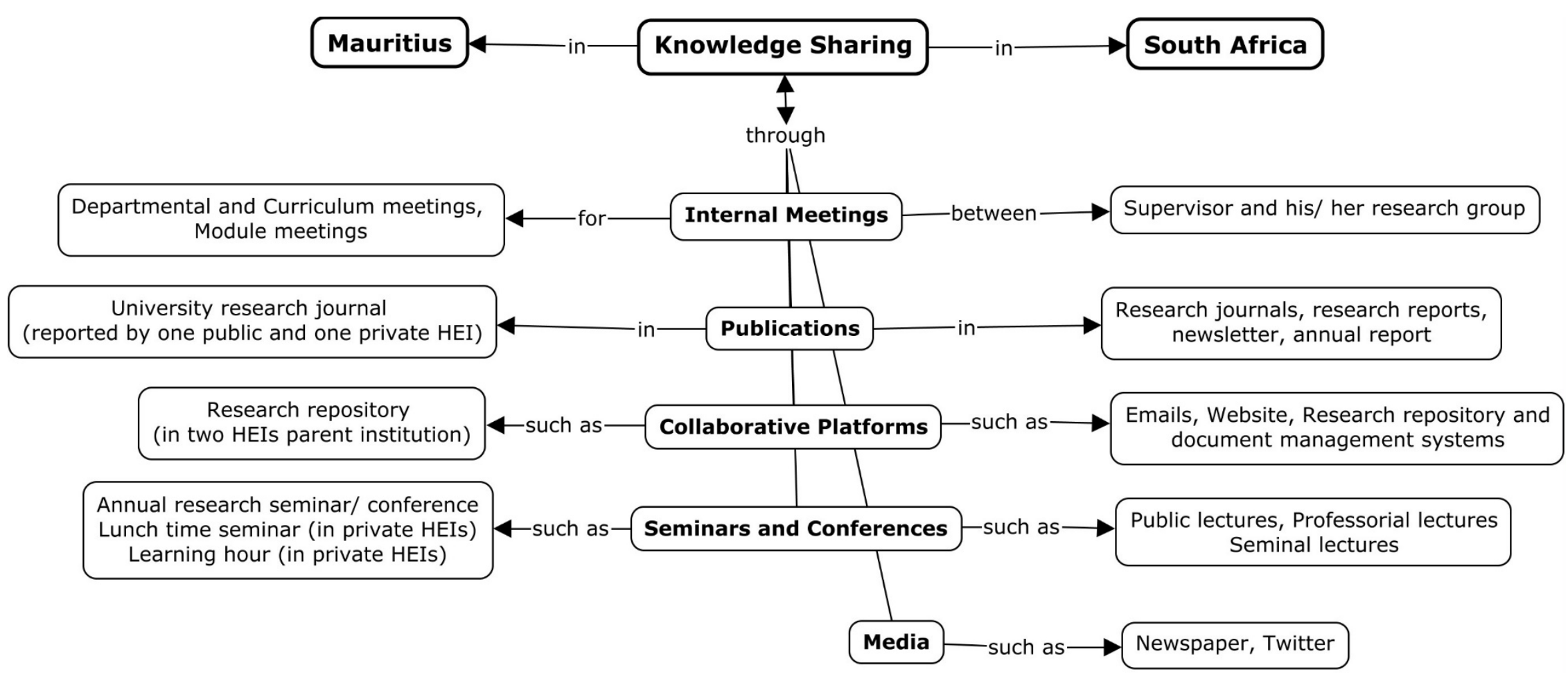


Figure 4: Knowledge transfer processes in HEIs of Mauritius and South Africa

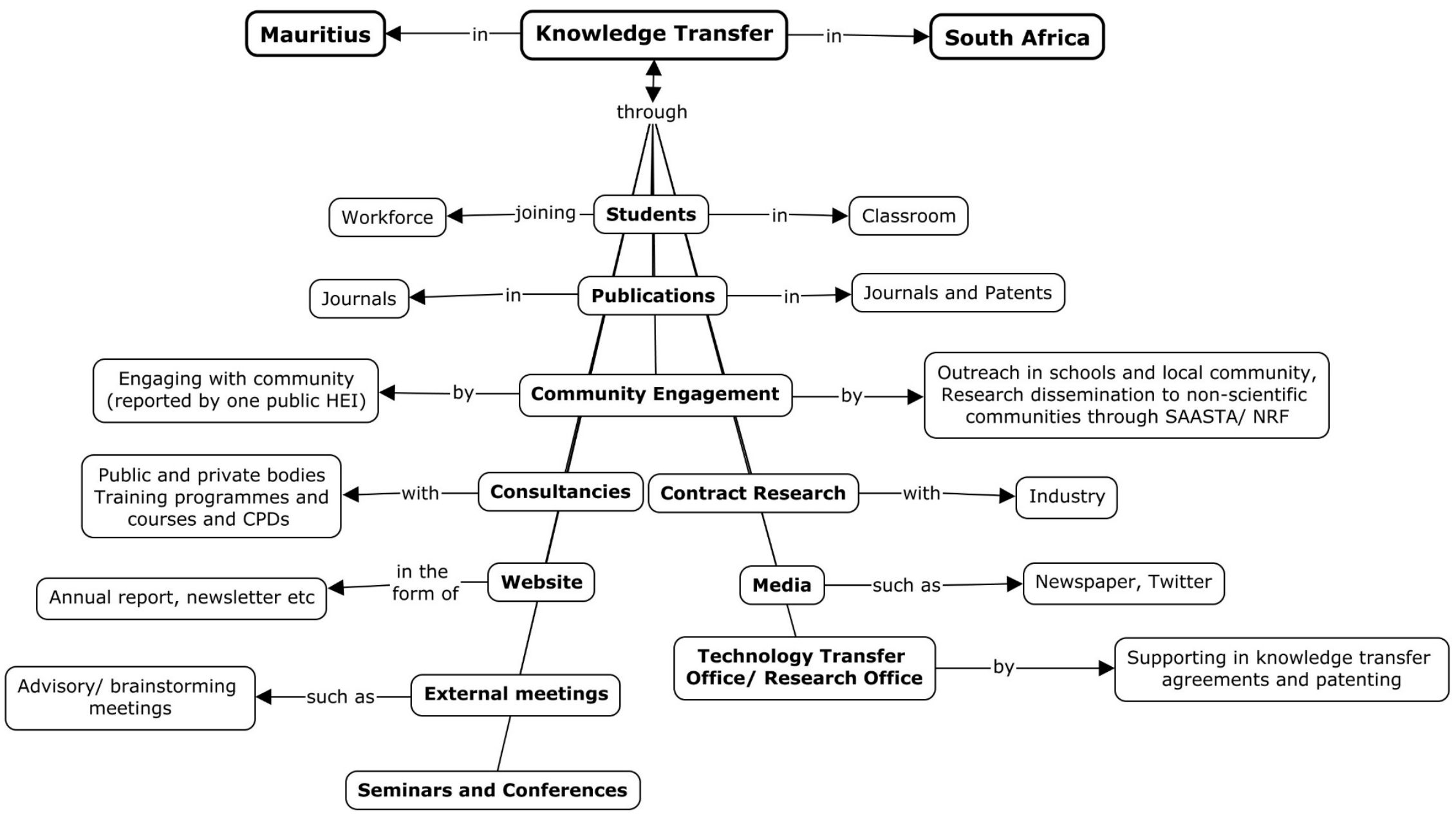

